\title{
A Recent Review of Vegetation Science in Japanese Geography
}

\author{
YOSHIDA Keiichiro \\ Faculty of Education and Human Science, Yokohama National University, \\ Yokohama 240-8501, Japan
}

\begin{abstract}
Vegetation science, the study of vegetation patterns and processes, is a relatively minor sub-field of geography in Japan. I summarize the major research on vegetation science by Japanese geographers with reference to similar studies conducted by plant ecologists, focusing on vegetation-environmental relationships. In a few decades, the studies on vegetation by Japanese geographers have generally adopted descriptive approaches that examined the spatial associations between vegetation patterns and environmental factors. However, these studies only demonstrated the covariation of environmental factors with vegetation patterns, whereas theoretical and empirical studies of the mechanistic aspects of the relationships between vegetation patterns and environmental factors were undertaken in plant ecology over a few decades. Thus, to better understand the relationships between vegetation and environment factors and enhance predictions of vegetation change in response to environmental change, I recommend that collaborative approaches to plant ecology, involving plant physiology, should be promoted in geographical studies of vegetation science in Japan.
\end{abstract}

Key words: geoecology, geographical comparative study, descriptive approach, vegetation science, vegetation-environmental relationship

\section{Introduction}

The geographic sub-field of vegetation science examines the spatial patterns and processes of plant species and communities, as well as the processes and relationships that affect their distributions. As one of the oldest themes of geographic inquiry, the study of vegetation engaged the founders of modern geography (e.g, Humboldt 1805), and has continued to develop into a modern science, with applications in environmental conservation and management (der Maarel 2006).

In Japan, plant ecologists have dominated the study on geographical patterns of vegetation. For example, phytosociologists completed vegetation maps of Japan in the 1980s (e.g., Miyawaki 1986). Kira (1948), a plant ecologist, proposed the climatic indices to explain the distribution of vegetation zones in Japan, and Ohsawa (1990) also applied these indices to the study of vegetational patterns in humid East Asia. More recently, researchers in plant ecology have also produced numerous theoretical and mechanistic studies of vegetation patterns (e.g., Nakamura 1990; Hiura 1995; Kikuzawa 1996; Homma 1997; Okitsu 1999; Nakashizuka 2001; Kohyama 2005).

Unfortunately, a small number of geographers in Japan primarily study vegetation or plant communities, making vegetation science a relatively minor sub-field of geography in Japan. Given the relative lack of studies of vegetation patterns and processes in Japanese geography, geographers have referred to reports by plant ecologists and have incorporated the fundamental theories and field survey methods of these disciplines. Consequently, many geographers consider the disciplinary boundaries between geography and plant ecology to be ambiguous in this study field.

Here, I review the recent research on vegetation science by Japanese geographers, with reference to similar studies conducted by plant ecologists. In particular, I will focus on vegetation-environment relationships, which have been discussed in relative detail in Japanese geography. 


\section{Geoecological Studies}

Since the beginning of vegetation science in Japan, its practitioners in geography have functionally and quantitatively analyzed a full range of interrelations between vegetation and environmental elements including geology, landforms, soil, and climate. These studies have generally not used theoretical or experimental approaches, but have instead examined the correlations between environmental factors and vegetation patterns and provided detailed descriptions of vegetation and environmental factors of specific areas (e.g., Takeuchi et al. 1986). These studies, which comprehensively examined the relationships between vegetation and environmental factors, were developed as part of the geoecological research thrust in Japan during the 1980s and 1990s.

Geoecology examines the full and complex set of interrelations between organisms or a biocoenosis and environmental factors (Troll 1972). Geoecology was introduced to Japan in the 1970s (Koizumi 1996), and geoecological studies examined mainly alpine and subalpine areas. Watanabe (1986) reported that landform, geology, and various conditions such as the snowmelt pattern or grain size of surface materials is correlated with the vegetation pattern of a cirque in the northern Japanese Alps. In another study, Mizuno (1990) examined the effect of landform on vegetation patterns in cirques of the northern Japanese Alps. Koizumi (1996) and Watanabe (2004) have reviewed and summarized most of the geoecological studies conducted in Japan. However, despite research advances in the 1980s and 1990s, relatively few recent geoecological studies have continued this avenue of research, a trend that can be explained by the greater importance given by geoecologists to the spatial associations between vegetation and related environmental factors.

\section{Landform and Vegetation Pattern}

The vegetation patterns in relation to microscale landforms could be easily observed in hilly and mountainous regions, and were a major theme of vegetation science in Japan. The vege- tation patterns are affected by two factors, the environmental factors mediated by landforms and geomorphic processes (Kikuchi 2001).

\section{Landform-mediated environmental factors}

The vegetation patterns are changed correspondingly along the landform gradients, because the environmental factors which directly affect the vegetation patterns can covary with landforms. The indirect effects of landforms on vegetation pattern typically result from variations in micro-climate, soil condition, and natural disturbance.

The differences in solar radiation on northand south-facing slope cause changes in microclimate which may affect the forest structure and species composition (Jones 1992). The warmer temperature in winter on the south-facing slope mainly formed the evergreen broad-leaved secondary forests at the border with deciduous secondary forests (Isogai 1994). Orito and Hoshino (1997) also showed the differences in forest structure and composition of cool-temperature forests due to late snow melting on the northfacing slopes. The wind direction and speed can also be strongly influenced by local landforms, where they change the vegetation patterns (e.g., Mizuno 1984).

The spatial distribution of soil characteristics, e.g., soil moisture, are highly correlated to topography at the local scale (Tamura 1987), and may affect vegetation patterns (Ishizuka 1977). The spatial distributions of vegetation types were often explained by the differences in soil moisture along a ridge-valley gradient in hilly and mountainous regions (e.g., Yanagisawa and Fujita 1999; Sawada et al. 2005). In particular, the groundwater flow provides a habitat for wetland forest development at the bottom of slopes (Kikuchi et al. 2002). Gotoh and Kikuchi (1997) similarly reported that Magnolia tomentosa, an indigenous wetland tree in Japan, always inhabits wet sites on the bottom of valleys in hilly land.

Natural disturbance regimes are considered important environmental factors controlling vegetation patterns and processes (Pickett and White 1985; Nakashizuka and Yamamoto 1987). Landforms also affect the formation of vegetation patterns by controlling natural disturbance 
regimes (Swanson et al. 1988). Takaoka and Sasa (1996) examined the relationship between fire history and present vegetation in the mixed forests of northern Japan, and found the vegetation patterns were caused by the difference of fire regime among slope aspects and topographic positions. Bellingham et al. (1996) reported the effects of a powerful typhoon on the primary warm temperate rainforest in Yakushima, and suggested that the spatial heterogeneity of the damage by typhoon caused by the vegetation pattern related to the topographic positions, as well as the patterns in Jamaican montane forests (Bellingham et al. 1995).

\section{Geomorphic processes}

Geomorphic processes are natural disturbances that directly influence vegetation patterns (Ito and Nakamura 1994). The vegetation patterns related to geomorphic processes have been recorded at many forest types in Japan (Kikuchi 2002).

Since slopes steeper than 30 degrees are widely distributed, slope processes. are important natural disturbances that directly influence vegetation patterns in hilly and montane regions of Japan (Nakamura 1990). Slope processes can change in relative intensity and frequency along topographic gradients, and in particular, the lower slope is characterized by relatively active processes of soil erosion, landslides and slope failure (Kikuchi and Miura 1993). Since the slope stability can strongly affect the vegetation patterns (Shimokawa and Jitosono 1984; Nakamura 1990), the transition in the vegetation mostly corresponded to the convex break between upper and lower slopes (Matsubayashi 1997; Takaoka 2001). Sakai and Ohsawa (1994) reported the vegetation pattern coincided with erosional condition in a warm-temperate hilly region, and also indicated that the vegetation was separated topographically into two species groups; late successional species dominated on the relatively stable slopes and pioneer species dominated on the unstable slopes. Hara et al. (1996) also found that the poorly developed vegetation consisting of pioneer broad-leaved species was seen on the lower slope in an evergreen broad-leaved forest, and suggested that the difference in stability of the land surface was the major cause of the differences in forest structure between the upper and lower slopes.

Natural disturbances are also key factors for the maintenance and regeneration of riparian forests in mountain regions (Kaneko 1995; Sakio 1997). The intensity and frequency of natural disturbances caused by fluvial processes can strongly affect the vegetation pattern and species coexistence in riparian forest (Nakamura 1995; Nakamura et al. 1997). Shin et al. (1999) reported that the mosaic pattern of riparian forests was developed by the frequent channel shifts in floodplain along the Azusa River in central Japan. Suzuki et al. (2002) also suggested that the heterogeneous site condition created by multiple disturbance regimes formed the vegetational mosaics in the Kanumazawa Riparian Research Forest, northern Japan.

Given the correspondence of spatial and temporal scales of topographic processes to forest dynamics (Nakamura 1990), many studies of plant ecology have demonstrated the relationships between geomorphic processes and vegetation patterns in the last two decades. However, over the same period, relatively few geographers examined the effects of topography-related natural disturbances on vegetation patterns (e.g., Shin et al. 1999; Takaoka 2001; Ogata 2003).

\section{Climate and Vegetation Pattern}

Geographical patterns of vegetation types in Japan are largely determined by the present climatic conditions, particularly temperature (Kira 1948; Ohsawa 1993; Matsui et al. 2004). For example, the northern (upper) limit of evergreen broad-leaved forests coincides closely to the $-1^{\circ} \mathrm{C}$ isotherm of monthly mean temperature in the coldest month (Ohsawa 1990). Several studies implied that these vegetation patterns were related to the physiological characteristics of the evergreen broad-leaved trees, such as freezing resistance (Sakai 1972), freeze-thaw embolism (Taneda and Tateno 2005), and leaf water relation (Harayama 2006).

Ecological responses to recent climate change are already clearly visible in many regions of the world (Walther et al. 2002), and the effects of climate change on forest ecosystems have become a major concern of many scientists since 
the turn of the 21st century (McCarthy et al. 2001). In Japan, potential plant distributions under climate change scenarios have been predicted in many studies (e.g., Kohyama and Shigesada 1995; Tsunekawa et al. 1996; Ishigami et al. 2003, 2005; Matsui et al. 2004). Most of these studies have predicted the potential distribution of natural vegetation under predicted climate change based mainly on the relationships between the dominant species and present climatic factors. However, effects of climate change on vegetation pattern will not only induce a shift of vegetation zone toward the north and higher elevations in a macro-scale, but also complex changes depending on the diverse controlling environmental factors in fine scales (Tanaka et al. 1998). Furthermore, the differential physiologic response of tree species to climate change should reflect the differences in species traits such as dispersal capacity and environmentaldependent responses of demographic processes (Kohyama and Shigesada 1995; Takenaka 2005). Therefore, further on-site observations and field experiments on the relationships between vegetation patterns and climatic factors are needed to predict more accurately the effects of climate change on vegetation (Kohyama 1996).

In line with this need, a number of geographical studies involving direct, on-site meteorological observation have provided information on the responses of vegetation to recent climate changes in several vegetation types. Because vegetation in tree line and alpine zones is particularly vulnerable and sensitive to climate conditions (Kullman 2001), several studies have conducted periodic and detailed meteorological observations in alpine and subalpine regions (Takahashi and Hasegawa 2003; Hamada et al. 2000). To predict the changes in community dynamics caused by climate change, a number of temperature manipulation studies have also been conducted mainly in alpine region of Japan (e.g., Kudo and Suzuki 2003; Zaiki et al. 2003; Takahashi 2005). A lot of moors with peat layer are distributed in the mountainous area of Tohoku and Kanto districts along the Sea of Japan, and their vegetation has been reduced recently (Yasuda and Okitsu 2007). Yasuda and Okitsu (2006) pointed out that the reduction of alpine moor on Mt. Hiragatake was associated with the recent decline in snow accumulation in the mountainous area. Recent studies at subtropical island sites have also suggested the effects of climate change on native vegetation. Japan's subtropical Ogasawara (Bonin) Islands showed a warming and drying trend in the twentieth century (Yoshida et al. 2006). Based on continual meteorological observations, Yoshida et al. (2002) reported that the seasonally dry edaphic conditions strongly affected the vegetation patterns of these subtropical islands. Their findings further implied that predicted climate changes would lead to significant vegetation changes on the Ogasawara (Bonin) Islands.

However, although they provide useful information, such studies of the relationships between climate change and vegetation have only demonstrated the covariation of climate conditions with vegetation patterns and have not elucidated the processes of vegetational changes in response to climate changes. In contrast, plant physiological ecologists have intensively studied the physiological processes underlying plant responses to environmental factors for many years (e.g., Lambers et al. 1998). Future studies of the mechanisms underlying climate-vegetation relationships combined with plant physiological knowledge are necessary to accurately comprehend vegetation changes in relation to climate changes.

\section{Geographical Comparative Studies}

Comparative studies have provided empirical evidence supporting the basic theories and principles of vegetation science. Using a comparative approach, a number of studies have attempted to clarify vegetation patterns and processes at relatively large spatial scales. Kitayama (1996) examined the relationships between regional floristic richness and species diversification by comparing an oceanic island with a continental island. He suggested from the results that sympatric and parapatric species radiation was less on the oceanic island than on the continental island, because of the initially poor and disharmonic flora on the oceanic island. Maruoka et al. (2003) compared vegetation along an altitude belt in spatially noncontiguous mountains to investigate geographic variation and habitat 
differentiation. They also suggested that multidimensional habitat differentiation increased with interspecific competition arising from species packing. Focusing on biological invasion, Yoshida (2001) compared successional paths in abandoned fields invaded by Leucaena leucocephala at oceanic and continental island sites. On the oceanic island, the invasion of this alien species altered the secondary successional path irreversibly (Yoshida and Oka 2004); in contrast, biological invasion did not affect the secondary successional path as seriously on the continental island, where dense thickets of Leucaena leucocephala were replaced directly by indigenous species of fast-growing secondary trees (Yoshida and Oka 2001). These results suggest that simple communities on oceanic islands are more susceptible to biological invasion than are diverse communities on continental islands (Yoshida 2001).

More recently, comparative geographical studies using research data on large plots ( $>1$ ha) of various forest types have been increasing especially in plant ecology. For example, Kanzaki et al. (2000) compared a tropical montane forest in Thailand with a temperate lucidophyll forest in Japan to examine the pattern of niche differentiation. They came to the preliminary conclusion that high species richness in a tropical forest was associated with fine topographical niche differentiation among the canopy tree species. Takyu et al. (2005) also examined how climate seasonality and the dominant life form affects the attributes of forest ecosystems by comparing these patterns along an altitudinal gradient from tropical to temperate regions of humid East Asia. Similarly, Aiba et al. (2007) compared forest ecosystems along elevational gradients at two World Natural Heritage Sites in eastern Asia, i.e., Yakushima Island, Japan, and Mount Kinabalu, Malaysia, and discussed the consequences of additive basal area for forest ecosystem function. Some vegetation science databases have also been developed in Japan (e.g., Forestry and Forest Products Research Institute 2003). These databases will likely be increasingly used in further comparative geographic studies in vegetation science and plant ecology.

\section{Conclusion}

Geographers specializing in vegetation science have long explored the relationships between vegetation and environmental factors at various spatial and temporal scales. However, most studies have provided descriptive reports without an explicit mechanistic basis, with only a few examining the processes underlying vegetation changes. On the other hand, plant ecologists have undertaken numerous theoretical and empirical studies of the mechanistic aspects of the relationships between biotic and abiotic factors within plants, plant communities, and ecosystems. Thus, to better understand the relationship between vegetation and environmental factors and thus enhance predictions of vegetation change in response to environmental change, future studies of vegetation in Japanese geography require collaborative approaches to plant ecology developed over several decades.

The recent improvements in networks among the ecological research sites and the accumulation of forest inventory data in plant ecology have promoted synthesis and comparative studies across sites and ecosystems in Japan (Tanaka and Hori 2001). Geographical comparative study is useful for an elucidation of the importance of various environmental and historical factors that operate at larger spatial and temporal scales, by which vegetation patterns have been shaped (Aiba et al. 2007). Although comparative studies have been traditionally conducted in geography, Japanese geographers have lagged behind in programs focusing on plant ecology. In the understanding of the vegetation patterns and processes in various spatial and temporal scales, we should pay attention to the insights from similar studies and the approaches of plant ecology.

\section{Acknowledgements}

I gratefully acknowledge valuable comments on an earlier version of this paper, and suggestions by Dr. Shuichi OKA.

(Received 4 July 2007) (Accepted 8 March 2008) 


\section{References}

Aiba, S., Hanya, G., Tsujino, R., Takyu, M., Seino, T., Kimura, K., and Kitayama, K. 2007. Comparative study of additive basal area of conifers in forest ecosystems along elevational gradients. Ecological Research 22: 439-450.

Bellingham, P. J., Tanner, E. V., and Healey J. R. 1995. Damage and responsiveness of Jamaican montane tree species after disturbance by a hurricane. Ecology 76: 2562-2580.

Bellingham, P. J., Kohyama, T., and Aiba, S. 1996. The effects of a typhoon on Japanese warm temperate rainforests. Ecological Research 11: 229-247.

Forestry and Forest Products Research Institute (FFPRI). 2003. Forest Dynamics Database. http://fddb.ffpri-108.affrc.go.jp/ (Last viewed date: Feb 21, 2008).

Gotoh, T., and Kikuchi, T. 1997. The Magnolia tomentosa community and its habitat on hilly land in the Tokai District, Japan. Japanese Journal of Ecology 47: 239-247. (JE)

Hamada, T., Kanno, H., and Oka, S. 2000. Climatic conditions near the forest limit on the northwestern slope of Mt. Fuji, Central Japan. Geographical Review of Japan 73A: 435-447. (JE)

Hara, M., Hirata, K., Fujihara, M., and Oono, K. 1996. Vegetation structure in relation to micro-landform in an evergreen broad-leaved forest on Amami Ohshima Island, south-west Japan. Ecological Research 11: 325-337.

Harayama, H. 2006. Seasonal variations in water relations in current-year leaves of evergreen trees with delayed greening. Tree Physiology 26: 1025-1033.

Hiura T. 1995. Gap formation and species diversity in Japanese beech forests: A test of the intermediate disturbance hypothesis on a geographic scale. Oecologia 104: 265-271.

Homma, K. 1997. Effects of snow pressure on growth form and life history of tree species in Japanese beech forest. Journal of Vegetation Science 8: 781-788.

Humboldt, A. von. 1805. Essai sur la geographie des plantes. Paris: Levrault, Schoell et Cie. (F)

Ishigami Y., Shimizu, Y., and Omasa, K. 2003. Projection of climatic change effects on potential natural vegetation distribution in Japan. Journal of Agricultural Meteorology 59: 269-276. (JE)

Ishigami, Y., Shimizu, Y., and Omasa, K. 2005. Evaluation of the risk to natural vegetation from climate change in Japan. Agricultural Meteorology 61: 69-75. (JE)
Ishizuka, K. ed. 1977. Distribution of plant communities and environment. Tokyo: Asakura-shoten. (J)

Isogai, T. 1994. Distribution of evergreen and summergreen broad-leaved secondary forests and its causal factors in a small drainage basin in southern Izu Peninsula, central Japan. Eco-Habitat 1: 15-31. (JE)

Ito, T., and Nakamura, F. 1994. Forest disturbance and regeneration in relation to earth surface movement. Japanese Journal of Forest Environment 36: 31-40. (JE)

Jones, H. G. 1992. Plants and microclimate: A quantitative approach to environmental plant physiology (second edition). Cambridge: Cambridge University Press.

Kaneko, Y. 1995. Disturbance regimes of a mountainous riparian forest and effects of disturbance on tree population dynamics. Japanese Journal of Ecology 45: 311-316. (J)

Kanzaki, M., Sri-Ngernyuang, K., Fujii, N., Mizuno, T., Noguchi, H., Yamakura, T., Hara, M., Sahunalu, P. Dhanmanonda, P., Bunyavejchewin, S., and Mathavararug, A. 2000. Comparative community ecology of tropical montane and temperate lucidophyll forests: Comparison of niche differentiation pattern. Tropics 9: 211-228. (JE)

Kikuchi, A., Onda, Y., and Nakagoshi, N. 2002. Groundwater flow in spring-fed wetland and the formation of vegetation patterns in Hiroshima Prefecture, southwestern Japan. Vegetation Science 19: 95-111. (JE)

Kikuchi, T. 2001. Vegetation and Landforms. Tokyo: University of Tokyo Press. (J)

Kikuchi, T. 2002. Landslide vegetation and its habitat condition. Journal of the Japan Landslide Society 39: 52-56. (J)

Kikuchi, T., and Miura, O. 1993. Vegetation patterns in relation to micro-scale landforms in hilly land regions. Vegetatio 106: 147-154.

Kikuzawa, K. 1996. Geographical distribution of leaf life span and species diversity of trees simulated by a leaf-longevity model. Vegetatio 122: 61-67.

Kira, T., 1948. On the altitudinal arrangement of climatic zones in Japan. Kanti-Nogaku 2: 142-173. (J)

Kitayama, K. 1996. Patterns of species diversity on an oceanic versus a continental island mountain: A hypothesis on species diversification. Journal of Vegetation Science 7: 879-888.

Kohyama, T. 1996. Integreted modeling: From forest canopy architecture to vegetation zonation. Japanese Journal of Ecology 46: 57-61. (JE)

Kohyama, T. 2005. Scaling up from shifting-gap mosaic to geographic distribution in the modeling of for- 
est dynamics. Ecological Research 20: 305-312.

Kohyama, T., and Shigesada, N. 1995. A size-distribution-based model of forest dynamics along a latitudinal environmental gradient. Vegetatio 121: $117-126$.

Koizumi, T. 1996. Recent progress in geoecology in Japan. Geographical Review of Japan 69B: 160-169.

Kudo, G., and Suzuki, S. 2003. Warming effects on growth, production, and vegetation structure of alpine shrubs: A five-year experiment in northern Japan. Oecologia 135: 280-287.

Kullman, L. 2001. 20th century climate warming and tree-limit rise in the southern Scandes of Sweden. Ambio 30: 72-80.

Lambers, H., Chapin, F. S., and Pons, T. L. 1998. Plant physiological ecology. New York: Springer.

McCarthy, J. J., Canziani, O. F., Leary, N. A., Dokken, D. J., and White, K. S. eds. 2001. Climate change 2001: Impacts, adaptation, and vulnerability. New York: Cambridge University Press.

Maruoka, H., Yoshida, K., and Oka, S. 2003. Geographic variation in habitat differentiation of subalpine forests in northeastern Japan. Japanese Journal of Ecology 53: 107-116. (JE)

Matsubayashi, T. 1997. A relationship between vegetation patch and landform in a small drainage basin in the Takadate Hills, northeastern Japan. Quarterly Journal of Geography 49: 247-261. (JE)

Matsui, T., Yagihashi, T., Nakaya, T., Nobuyuki, T., and Taoda, H. 2004. Climatic controls on distribution of Fagus crenata forests in Japan. Journal of Vegetation Science 15: 57-66.

Miyawaki, A. ed. 1986. Vegetation of Japan. Vol. 7 Kanto. Tokyo: Shibundo. (JE)

Mizuno, K. 1984. Habitat types of Ohanabatake vegetation in the Akashi Mountains, central Japan. Geographical Review of Japan 57A: 384-402. (JE)

Mizuno, K. 1990. Distribution of plant communities in relation to environments in the cirques of the Northern Japan Alps. Geographical Review of Japan 63A: 127-153. (JE)

Nakamura, F. 1990. Perspectives for the effects of geomorphic processes. Biological Science 42: $57-67 .(\mathrm{J})$

Nakamura, F. 1995. Forest and stream interactions in riparian zone. Japanese Journal of Ecology 45: 295-300. (J)

Nakamura, F., Yajima, T., and Kikuchi, S. 1997. Structure and composition of riparian forests with special reference to geomorphic site conditions along the Tokachi River, northern Japan. Plant Ecology 133: 209-219.

Nakashizuka, T. 2001. Species coexistence in temper- ate, mixed deciduous forest. Trends in Ecology \& Evolution 16: 205-210.

Nakashizuka, T., and Yamamoto, S. 1987. Natural disturbance and stability of forest community. Japanese Journal of Ecology 37: 19-30. (JE)

Ogata, T. 2003. Physiographic factors controlling the degradation of the moor at the foot of an alluvial fan in the Senjogahara, Nikko National Park, Japan. Geographical Review of Japan 76: 1025-1039. (JE)

Ohsawa, M. 1990. An interpretation of latitudinal patterns of forest limits in south and east Asian mountains. Journal of Ecology 78: 326-339.

Ohsawa, M. 1993. Latitudinal pattern of mountain vegetation zonation in southern and eastern Asia. Journal of Vegetation Science 4: 13-18.

Okitsu, S. 1999. Distribution of the forests of the boreal zone of northeastern Asia and conditions for the establishment of the forest boundaries. Vegetation Science 16: 83-97. (JE)

Orito, A., and Hoshino, Y. 1997. Compositional and structural difference in forest stands between south- and north-facing slopes in cool temperate Oku-Nikko and Oku-Kinu regions, central Japan. Vegetation Science 14: 77-89. (JE)

Pickett, S. T. A., and White, P. S. 1985. The ecology of natural disturbance and patch dynamics. San Diego: Academic Press.

Sakai, A. 1972. Freezing resistance to evergreen and broad-leaf trees indigenous to Japan. Journal of the Japanese Forestry Society 54: 333-339. (JE)

Sakai, A., and Ohsawa, M. 1994. Topographical pattern of the forest vegetation on a river basin in a warm-temperate hilly region, central Japan. Ecological Research 9: 269-280.

Sakio, H. 1997. Effects of natural disturbance on the regeneration of riparian forests in a Chichibu Mountains, central Japan. Plant Ecology 132: 181-195.

Sawada, H., Ohkubo, T., Kaji, M., and Oomura, K. 2005. Spatial distribution and topographic dependence of vegetation types and tree populations of natural forest in the Chichibu Mountains, central Japan. Journal of the Japanese Forest Society 87: 293-303. (JE)

Shimokawa, E., and Jitousono, T. 1984. Residence time of soil on slopes and Yaku-sugi (Cryptomeria japonica) in the Yaku-shima Wilderness Area, Yaku-shima Island. In Conservation reports of the Yaku-shima Wilderness Area, Kyusyu, Japan, ed. Nature Conservation Bureau, Environment Agency, Japan. 83-100. Tokyo: Environment Agency, Japan. (J)

Shin, N., Ishikawa, S., and Iwata, S. 1999. The mosaic 
structure of riparian forest and its formation pattern along the Azusa River, Kamikochi, central Japan. Japanese Journal of Ecology 49: 71-81. (JE)

Suzuki, W., Osumi, K., Masaki, T., Takahashi, K., Daimaru, H., and Hoshizaki, K. 2002. Disturbance regimes and community structures of a riparian and an adjacent terrace stand in the Kanumazawa Riparian Research Forest, northern Japan. Forest Ecology and Management 157: 285-301.

Swanson, F. J., Kratz, T. K., Caine, N., and Woodmansee, R. G. 1988. Landform effects on ecosystem patterns and processes. BioScience 38 : 92-98.

Takahashi, K. 2005. Effects of artificial warming on shoot elongation of alpine dwarf pine (Pinus pumila) on Mt. Shogigashira, central Japan. Arctic, Antarctic, and Alpine Research 37: 620-625.

Takahashi, N., and Hasegawa, H. 2003. Forest line altitude and periglacial environment on the Jounennokkoshi Pass, the Northern Japanese Alps, estimated from air temperature observation data. Geographical Review of Japan 76: 161-171. (JE)

Takaoka, S. 2001. Mountain slope evolution controlling the distribution of Fagus crenata in the Kamikochi Valley, central Japan. Vegetation Science 18: 87-97. (JE)

Takaoka, S., and Sasa, K. 1996. Landform effects on fire behavior and post-fire regeneration in the mixed forests of northern Japan. Ecological Research 11: 339-349.

Takenaka, A. 2005. Local coexistence of tree species and the dynamics of global distribution pattern along an environmental gradient: A simulation study. Ecological Research 20: 297-304.

Takeuchi, K., Tamura, T., and Miyagi, Y. 1986. Geoecological study on the relationship between actual vegetation and its environment on a small subtropical island-A case study in the Yatsuse River Basin, Chichi-jima, the Ogasawara (Bonin) Islands, Japan. Ogasawara Research 6: 1-34. (JE)

Takyu, M., Kubota, Y., Aiba, S., Seino, T., and Nishimura, T. 2005. Pattern of changes in species diversity, structure and dynamics of forest ecosystems along latitudinal gradients in East Asia. Ecological Research 20: 287-296.

Tamura, T. 1987. Landform-soil features of the humid temperate hills. Pedologist 31: 135-146. (J)

Tanaka, N., Taoda, H., and Omasa, K. 1998. Field studies on the effects of global warming on mountain vegetation in Japan. Global Environmental Research 1: 71-74. (J)

Tanaka, K., and Hori, M. 2001. Towards establishment of the open and systematic framework for field research in Japan. Japanese Journal of Ecology 51: 255-259.

Taneda, H., and Tateno, M. 2005. Hydraulic conductivity, photosynthesis and leaf water balance in six evergreen woody species from fall to winter. Tree Physiology 25: 299-306.

Troll, C. 1972. Geoecology and the world-wide differentiation of high-mountain ecosystems. In Geoecology of the high-mountain regions of Eurasia, ed. C. Troll, 1-13. Wiesbaden: Franz Steiner Verlag.

Tsunekawa, A., Ikeguchi, H., and Omasa, K. 1996. Prediction of Japanese potential vegetation distribution in response to climate change. In Climate change and plants in East Asia, ed. K. Omasa, K. Kai, H. Taoda, Z. Uchijima and M. Yoshino, 57-65. Tokyo: Springer-Verlag.

van der Maarel, E. 2005. Vegetation ecology-An overview. In Vegetation ecology, ed. E. van der Maarel, 1-51. Oxford: Blackwell Publishers.

Walther, G. R., Post, E., Convey, P., Menzel, A., Parmesan, C., Beebee, T. J. C., Fromentin, J. M., Guldberg, H. O., and Bairlein, F. 2002. Ecological responses to recent climate change. Nature 416: 389-395.

Watanabe, T. 1986. Vegetation landscape and related alpine environmental factors of the Kuranosuke cirque Tateyama range, Northern Japanese Alps. Geographical Review of Japan 59A: 404-425. (JE)

Watanabe, T. 2004. Fragility of mountain geoecosystem and present situation and agendas of geoecological studies. Journal of Geography 113: 180-190. (JE)

Yanagisawa, N., and Fujita, N. 1999. Different distribution patterns of woody species on a slope in relation to vertical root distribution and dynamics of soil moisture profiles. Ecological Research 14: 165-177.

Yasuda, M., and Okitsu, S. 2006. Secular fluctuation of snowfall in the mountainous area of the Jyoetsu Border in relation to vegetation changes on Mt. Hiragatake. Geographical Review of Japan 79: 503-515. (JE)

Yasuda, M., and Okitsu, S. 2007. The factor in the reduction of alpine moors in the heavy snow areas along the Sea of Japan in eastern Japan. Hort Research 61: 1-5. (JE)

Yoshida, K. 2001. A biogeographical study on the vulnerability of island ecosystems to biological invasion by Leucaena leucocephala (Lam.) de Wit: Comparison of the Ryukyu and Ogasawara Islands in the north-western Pacific. Ph.D thesis, Tokyo 
Metropolitan University.

Yoshida, K., and Oka, S. 2001. Pattern of secondary succession in anthropogenic habitats on Miyakojima Island, the Ryukyu Islands, north-western $\mathrm{Pa}$ cific. Geographical Reports of Tokyo Metropolitan University 36: 1-10.

Yohisda, K., and Oka, S. 2004. Invasion of Leucaena leucocephala and its effects on the native plant community in the Ogasawara (Bonin) Islands. Weed Technology 18: 1371-1375.

Yoshida, K., Iijima, Y., Iwashita, H., and Oka, S. 2002. Hydroclimatic conditions in subtropical dry scrub on Chichi-jima Island, the Ogasawara (Bonin) Islands. Journal of Geography 111: 711-725. (JE)
Yoshida, K., Iwashita, H., Iijima, Y., and Oka, S. 2006. Long-term change in the hydroclimatic environment during the 20th century on Chichi-jima in the Ogasawara (Bonin) Islands. Geographical Review of Japan 79: 516-526. (JE)

Zaiki, M., Tsukada, Y., Fukuyo, S., and GENET. 2003. Change in alpine plant distribution during artifcial warming experiment at Mt. Kisokomagatake, central Japan. Theory and Applications of GIS 11: 23-31. (JE)

(J): written in Japanese

(JE): written in Japanese with English abstract

(F): written in French 